\title{
The Aphasia Screening test (A.S.T.): a pilot study, and validation of
} the test for the Greek Aphasic population Dionysios Tafiadis*1, Antonia Mperde ${ }^{1}$, Xristianna Panagiotou ${ }^{1}$, Maria Tafiadi ${ }^{2}$ and Eupraxia Tsanousa ${ }^{3}$

\author{
Address: ${ }^{1}$ Department of Speech Language Therapy, Technological Institute of Ioannina, Ioannina Greece, ${ }^{2}$ Department of Mathematics, \\ University of Patras, Patras, Greece and ${ }^{3}$ Department of primary education, University of Ioannina, Ioannina, Greece \\ * Corresponding author
}

\author{
from International Society on Brain and Behaviour: 3rd International Congress on Brain and Behaviour \\ Thessaloniki, Greece. 28 November - 2 December 2007 \\ Published: 17 April 2008 \\ Annals of General Psychiatry 2008, 7(Suppl I):S29I doi:10.1 186/I744-859X-7-SI-S29I
}

This abstract is available from: http://www.annals-general-psychiatry.com/content/7/SI/S29I

(c) 2008 Tafiadis et al.; licensee BioMed Central Ltd.

\section{Background}

The present research was a pilot study and validation of an adults' aphasia test for the Greek population. The Aphasia Screening Test for adult's aphasia (A.S.T.) was originally created by Renata Whurr from the existing battery tests and from her exercises. The 1st edition was published in (1974) and its purpose is a fast assessment and rating of adult's aphasia. The 2 nd edition was created after a long turn reliability researches by the same author in 1996.

\section{Materials and methods}

In this research took part 100 participants (50 aphasic and 50 non - aphasics subjects) recruited from the Greek health setting - region of Attica. The screening test was administered to all aphasic and non - aphasic participants. The sample was taken in random order; it was independent from origin and socio - economic situations. It was aged from 45 till 91 years of age [aphasics (min: 49, max: 91, mean: 68.72, strd.v. 11.52) and non - aphasics (min: 45, max: 85, mean: 60.24, strd.v. 10.62)], for the total of the sample. Also an ENT, psychiatric, neurological and a psychological examination were also requested. All the subjects had no other medical problems that could probably influence the test results.

\section{Results}

Statistical analysis of the data revealed that the results obtained are generally consistent with the results reported in other countries. No statistically significant differences were found between the results obtained for the Greek population and the results reported in the USA population in all diagnostic categories and the subtests the test has.

\section{Conclusions}

The test appears to be sensitive to adult aphasic symptomatology in the Greek population and presents satisfactory criterion and content validity as the aphasic participants assessed demonstrated clear patterns of deficit. The usefulness of the battery for the Greek population in clinical and research settings is also discussed. 